ISSN 1991- 8690

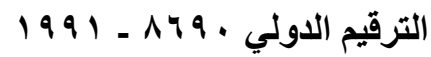

Website: http://jsci.utq.edu.iq

Email: utjsci@utq.edu.iq

\title{
Quantum Chemical QSPR Study of The Parameters Influences on Viscosity ( $\eta$ ) for Some Aniline Derivatives
}

\author{
Sadiq M-H. Ismael \\ Department of Chemistry - College of Education Pure Science \\ University of Basrah - Iraq \\ E-mail: sadiq.ismael.is@gmail.com
}

\begin{abstract}
Quantitative Structure-Property Relationship (QSPR) analysis to viscosity ( $\eta$ ) of 9 aniline derivatives have been conducted. The study was done by using molecular modelling of aniline compounds. The calculation was performed by the DFT method at B3PW91/6-31G $(\mathrm{d}, \mathrm{p})$ level of theory. The relationship analysis between viscosity $(\eta)$ and physicochemical properties of aniline compounds was done by MLR analysis, with viscosity $(\eta)$ as dependent variable and 9 independent variables to generate the equation that relates the structural features to the viscosity $(\eta)$ properties. The results show good models with four parameters linear equations. The best model predicted in this study is the four parametric regression equation (Eq. 6) In which the descriptors [Volume, T.E, surface(A) and Charge of N7] are included, with values of $\mathrm{R} 2=0.924, \mathrm{~F}=12.169$ and $\mathrm{S}=0.517, \mathrm{Ra} 2=0.848$ which indicate that these parameters, play an important role in effect on viscosity $(\eta)$ values.
\end{abstract}

Keywords: Aniline compounds, Viscosity $(\eta)$, (QSPR) Model.

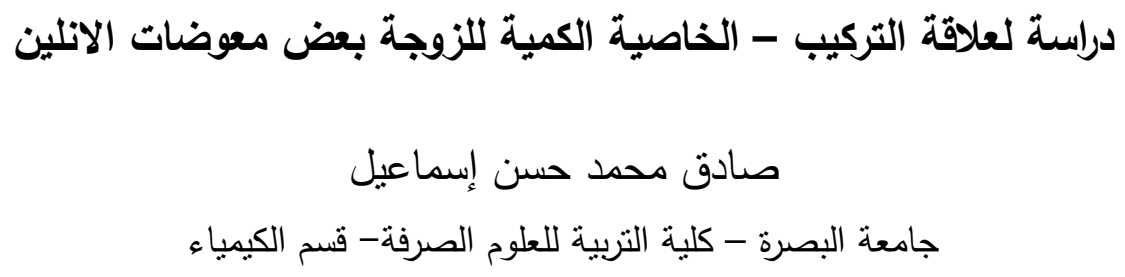

الخلاصة

تم حساب المتغيرات الفيزيوكيميائية لتسعة من معوضات الانيلين عند الطاقة الدنيا بطريقة(DFT) B3PW91) وعند مستوى المجاميع الاساسية لألتنبأ باللزوجة .انجزت المعادلات التي تربط الصفات التركيبية

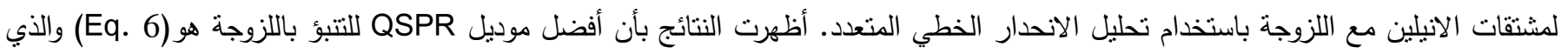

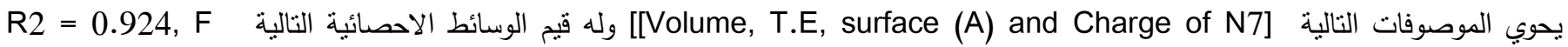
ومن هذا الموديل بينت الدراسة التأثير المميز لهذه الموصوفات على اللزوجة لمشتقات الانيلين الددروسة. 


\section{Introduction}

The physical properties of solution such as density, viscosity, refractive index etc. mostly depend on the solvent and solute present in the system. These parameters are related with molecular interactions among the solute and solvent [1]. Fluid flow plays a very important part in the processing of materials. Most processes are based on the use of fluids either as raw materials, reagents, or heat transfer media. The behavior of a fluid in flow is very much related to two intrinsic properties of the fluid: density and viscosity $(\eta)$. Viscosity is a measure of the resistance of a fluid which is being deformed by either shear stress or tensile stress[2]. Viscosity describes a fluid's internal resistance to flow and may be thought of as a measure of fluid friction [3-6]. These physical properties play important role in various applications in the field biological systems, industrial application(e.g, petroleum chemistry[7]), which diverse as fluid flow in pipes, the flow of blood, lubrication of engine parts, the dynamics of raindrops and volcanic eruptions, all involve fluid flow and are controlled to some degree by fluid viscosity etc[8].

Aniline compounds are an organic compound consisting of a phenyl group attached to an amino group also having various applications in the field of medicine, dye industry etc[9-11]. In the other hand QSPR/QSAR study is an important section in computational chemistry and uses frequently for predicting physico - chemical and biological activity of organic compounds, the basic strategy of QSPR is to find the optimum quantitative relationship, which can then be used for the predication of the properties of molecular structures including those unmeasured or even unknown[11-15]. Considerable work along these lines has been reported to predicting viscosity[16-19]. In this paper we use differents descriptors by using sequential multiple regression analysis (MLR) method was applied in quantitative structure-property relationships (QSPR) for modeling the relationship between viscosity $(\eta)$ of 9 aniline compounds as described in Ref [20] and their structural descriptors and predicated it theoretically.

\section{Modeling \& Geometry Optimization}

The quantum chemical calculations were performed for 9 compounds understudy with the Gaussain [21]. Geometrical optimizations were carried out using Density Functional Theory (DFT) method at B3PW91/6-31G(d,p)level of theory[22] and computed QSAR properties Surface grid (G), Surface approx(A), Hydration Energy, Volume, Polarizability, Refractivity and $\log$ P(P:Partition coefficient value is measure of lipophilicity of compound in an octanol-water system) by hyperchem 7.5 software. The experimental viscosity ( $\eta$ ) data of aniline and substited compounds under study has been taken from reference [20]. Structures of 9 aniline substited compounds shown in Figure.1
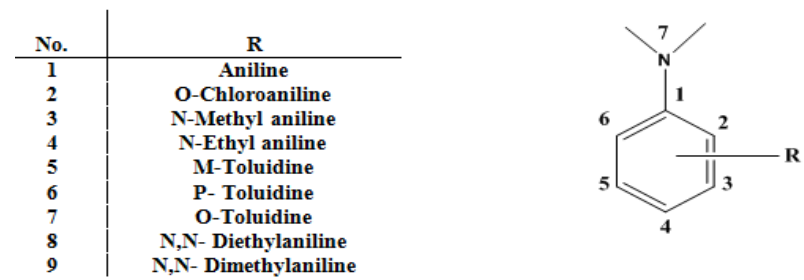

Figure 1. Molecular structure of aniline derivatives used in the present study

\section{Results and Discussion}

The relationship between viscosity $(\eta)$ and various descriptors (Physiochemical and alignmentindependent) were established by sequential multiple regression analysis (MLR) in order to obtain QSPR models. The best multilinear regression (BMLR) procedure was used to find the best correlation models from the selected noncollinear descriptors. The descriptors Table 1., which were significant for experimental data, were selected by QSPRcontingency module. To establish the statistical correlation, the physicochemical parameters were taken as independent variables and viscosity ( $\eta$ )as dependent variable. The best model was selected on the basis of statistical parameters viz observed with high coefficient of multiple (R2), sequential Fischer test $(\mathrm{F})$, low standard error of estimate (S), and adjusted coefficient of multiple determination (Ra2). were employed to judge the validity of regression equation and evaluate the obtained QSPR models[2324].

Table 1. Calculated physico-chemical parameters of the compounds

\begin{tabular}{|c|c|c|c|c|c|c|c|c|c|c|c|c|c|}
\hline & HOMO & LUMC & $\Delta \mathrm{E}$ & T.E & D.M & $Q_{s}$ & H.E & Ref & Pol & Log & Volum & $\begin{array}{l}\text { Surf } \\
\text { (A) }\end{array}$ & surf \\
\hline & -5.2341 & 0.277 & 5.5114 & -287.56 & 2.0068 & -0.7301 & -6.08 & 30.68 & 12.46 & $\begin{array}{l}r \\
1.09\end{array}$ & 365.64 & 204.54 & $\frac{(G)}{258.31}$ \\
\hline & -5.541 & -0.11 & 4238 & 7.050 & 046 & -0.73 & -5.12 & 35.49 & 14.38 & 1.61 & 404.08 & 229.58 & 276.4 \\
\hline s & & 0.22 & 5.4 & & & & & & & 2 & & & \\
\hline 4 & & 0.3055 & & & & & -3.21 & & & 9 & & & \\
\hline & & & & & & & -4.62 & & & $\begin{array}{l}1.56 \\
1.56\end{array}$ & & & \\
\hline & $\begin{array}{r}-4.9963 \\
-5.1549\end{array}$ & 0.3809 & 5.5356 & $\begin{array}{l}-325.007 \\
-326812\end{array}$ & 2.0923 & -0.7318 & $-4,27$ & 3572 & 14.29 & 1.56 & & 20974 & 280.91 \\
\hline & -4.9979 & 0.3311 & 5.3291 & -444.681 & 2.3068 & -0.5473 & -0.38 & 49.98 & 19.12 & 3 & $\begin{array}{l}1510.02 \\
553.52\end{array}$ & 340.82 & 1.91 \\
\hline & 0254 & & 5.3244 & 66.096 & 8887 & -0.5316 & .38 & 0.41 & 16.13 & 2.41 & 461.6 & .53 & \\
\hline
\end{tabular}

Definition of Descriptors Used in This Study HOMO: The energy of Highest Occupied Molecular Orbital in ev, LUMO: The energy of Lowest Unoccupied Molecular Orbital in ev $\Delta \mathrm{E}=\varepsilon_{\mathrm{LUMO}^{-}}$

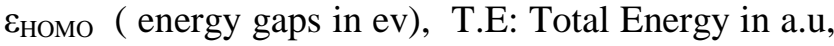


D.M: Dipole moment in debyes, $\mathrm{Q}_{\mathrm{N}}$ : Mullikan atomic charge on $\mathrm{N}$ atom number 7, H.E: Hydration Energy in Kcal/mol, Ref: Refractivity , Pol:Polarizability, LogP:logarithim of partition coefficient, Volume in $\mathrm{Ang}^{3}$, Surf(A): Surface area $\operatorname{approx}(\mathrm{A})$ in $\mathrm{cm}^{2}$ and $\operatorname{Surf}(\mathrm{G})$ : Surface area $\operatorname{grid}(\mathrm{G})$ in $\mathrm{cm}^{2}$.

The next most important descriptors involved in the QSPR models are the HOMO energy, LUMO energy, HOMO-LUMO energy gap $(\Delta \mathrm{E})$, Dipole moment, charge, Total Energy, Hydration Energy, refractivety, LogP, volume, surface $(\mathrm{A})$, surface $(\mathrm{G})$, can be directly related with experimental data of viscosity $(\eta)$. The 1 and 13- descriptor correlations of the viscosity $(\eta)$ were given in eqs (1-6) respectively and the resulting parametric models are depicted in figures. 2-6, along with statistical parameters of the regression. The first model which depends on only one- descriptor [E.Gap] gave weak model with correlation coefficient R2 values for this model of 0.335 , as eq 1 .

$\eta=10.361(+/-19.279)$ E.Gap-53.132(+/-104.66) ------- 1

Statistical characteristics of the obtained equation:

$R 2=0.335 \quad F=3.536 \quad S=1.157 \quad \mathrm{Ra} 2=0.240$ Fig.

2 , shows the relationship between the experimental viscosity $(\eta)$ data and predicted viscosity $(\eta)$ by this model.

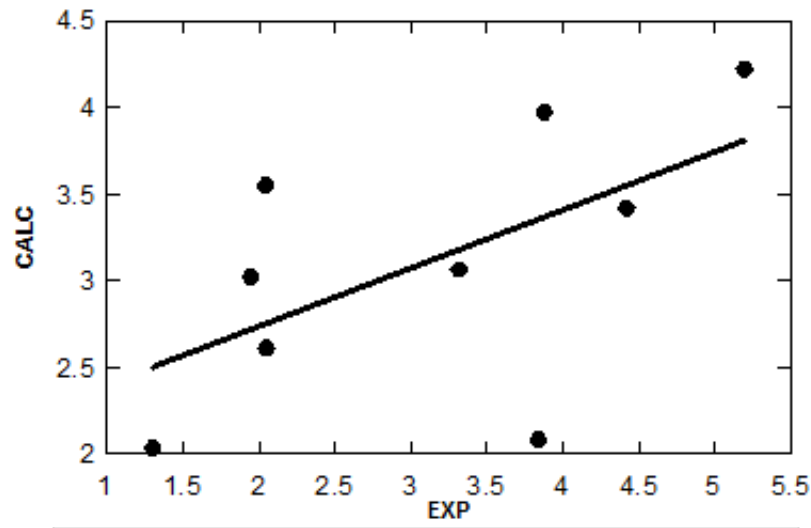

Fig 2. The relationships between experimental $(\eta)$ and predicted $(\eta)$ by model (1).

While in the eq.2, two descriptors, the good correlation coefficient R2 obtained when add the descriptors Pol to E.Gap, on the other hand in the eq 2. It can be seen decrease the standard error comparable with eq 1 .

$\eta=-149.955(+/-97.388)+0.7428(+/-0.6347)$

Pol+26.150(+/-16.480)E.Gap ----- 2

Statistical characteristics of the obtained equation:

$\mathrm{R}^{2}=0.719 \quad \mathrm{~F}=7.687 \mathrm{~S}=0.812 \quad \mathrm{Ra}^{2}=0.625$
Fig. 3, shows the relationship between the experimental $(\eta)$ data and predicted $(\eta)$ by this model.

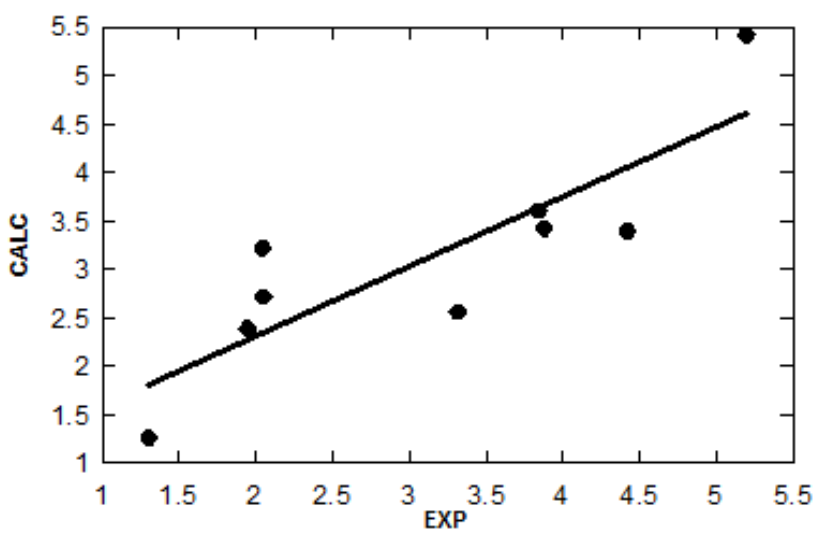

Fig 3. The relationships between experimental $(\eta)$ and predicted $(\eta)$ by model $(2)$.

with three descriptors eq 3 the viscosity $(\eta)$ of compounds increases with the descriptors [Pol, E.Gap and surface $(\mathrm{G})]$. in this eq 3 . depends on three descriptors gave very good model with change in the correlation coefficient $\mathrm{R}^{2}$ values to 0.870 , high sequential Fischer test $(\mathrm{F})$ and the low standard error of estimate (S).

$\eta=1.982(+/-2.191)$ Pol+25.657(+/-20.123)E.Gap$8.883 \times 10^{-2}(+/-0.146)$ surface $(\mathrm{G})-139.651(+/-120.036)$ ------ 3

Statistical characteristics of the obtained equation: $\mathrm{R} 2=0.871 \quad \mathrm{~F}=11.33 \quad \mathrm{~S}=0.601 \quad \mathrm{Ra} 2=0.794$ Fig. 4, shows the relationship between the experimental $(\eta)$ data and predicted $(\eta)$ by this model.

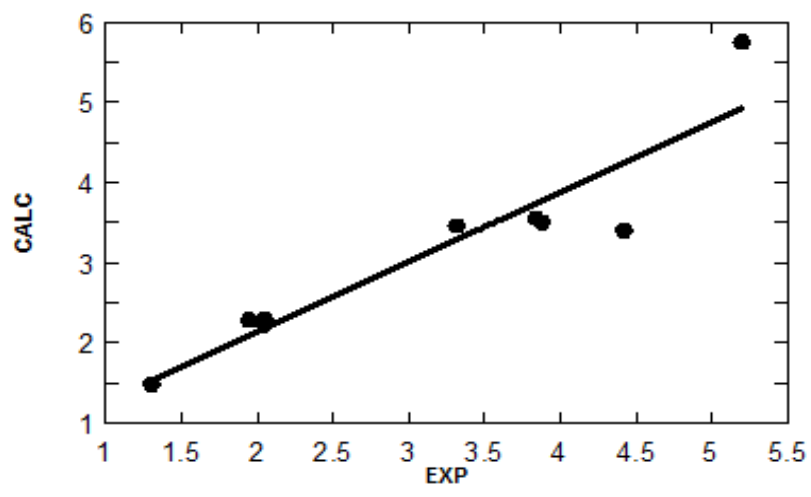

Fig. 4. The relationships between experimental $(\eta)$ and predicted $(\eta)$ by model ( 3$)$.

In eq 4. Also when using three descriptors [Pol, E.Gap and surface (A)] by replacement surface $(G)$ in eq 3. by surface (A) in eq 4. As seen from this 
resulting in a very minor improvement of the correlation coefficient, standard error and of the sequential Fischer test (F), in contrast with eq 3. This indicted that these descriptors have positive effect on viscosity ( $\eta$ ) properties of aniline compounds understudy.

$\eta=1.314(+/-1.197)$ Pol+19.950(+/-22.220)E.Gap-

$3.716 \times 10^{-2}\left(+/-5.998 \times 10^{-2}\right)$ surface(A)-115.137

$(+/-130.014) \quad---------4$

Statistical characteristics of the obtained equation:

$\mathrm{R} 2=0.875 \mathrm{~F}=11.683 \mathrm{~S}=0.593 \mathrm{Ra} 2=0.800$

Fig. 5, shows the relationship between the experimental $(\eta)$ data and predicted $(\eta)$ by this model.

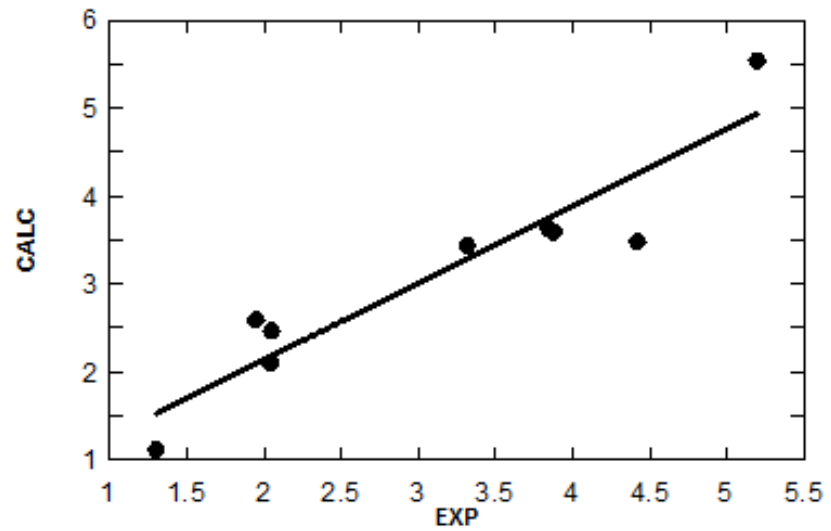

Fig 5. The relationships between experimental $(\eta)$ and predicted $(\eta)$ by model (4).

In eq 5. Also when using four descriptors [Volume, E.Gap , surface(A) and Charge of $\mathrm{N}_{7}$ ] by add the Charge of $\mathrm{N}_{7}$ in eq 4. This leads to generat eq 5. As seen from this resulting in a very minor improvement of the correlation coefficient, standard error and of the sequential Fischer test $(\mathrm{F})$, in contrast with eq 3. This indicated that these descriptors have positive effect on viscosity $(\eta)$ properties of aniline derivatives understudy.

$\eta=7.745(+/-7.453 \times 10-2)$ Volume $+7.761(+/-$

26.196)E.Gap-0.1058(+/-

$0.1282)$ surface $(\mathrm{A})+6.275(+/-14.715)$

$\mathrm{Q}_{\mathrm{N}}-40.851(+/-155.716)-----5$

Statistical characteristics of the obtained equation:
$\mathrm{R}^{2}=0.909$
$\mathrm{F}=10.007$
$S=0.566$

$\mathrm{Ra}^{2}=0.818$

Fig. 6, shows the relationship between the experimental $(\eta)$ data and predicted $(\eta)$ by this model.

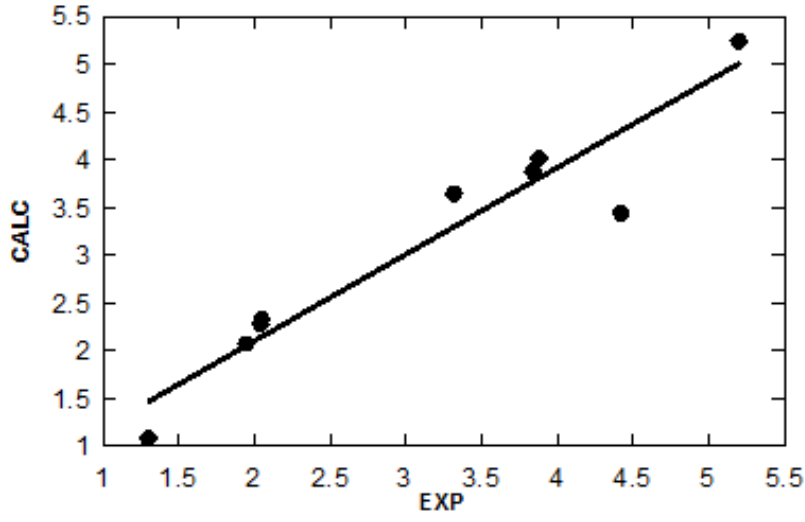

Fig 6. The relationships between experimental $(\eta)$ and predicted $(\eta)$ by model ( 5$)$.

In eq 6. Also when using four descriptors [Volume, T.E, surface(A) and Charge of N7] by replacement the E.Gap in eq 5. by T.E in eq 6. As seen from this resulting in a very excellent improvement of the correlation coefficient, standard error and of the sequential Fischer test (F), in contrast with eq 5. This indicated that these descriptors which has a positive value in front of [ T.E, Volume and Charge of N7] refers to a positive correlation with viscosity $(\eta)$ in contrast the negative value in front of [ surface (A)] refers to the inverse relationship with viscosity.

$\eta=9.288 \times 10^{-2}\left(6.684 \times 10^{-2}\right)$ Volume $+2.370 \times(+/-$ $6.287 \times 10^{-3}$ T.E-0.1399(+/-9.572 $\left.\times 10^{-2}\right) \operatorname{surface}(\mathrm{A})$ $+8.416(+/-12.841) \mathrm{Q}_{\mathrm{N}}+5.839(+/-14.795)$----- 6

Statistical characteristics of the obtained equation: $\mathrm{R}^{2}=0.924 \quad \mathrm{~F}=12.169 \quad \mathrm{~S}=0.517 \quad \mathrm{Ra}^{2}=$ 0.848

Fig. 7, shows the relationship between the experimental $(\eta)$ data and predicted $(\eta)$ by this model.

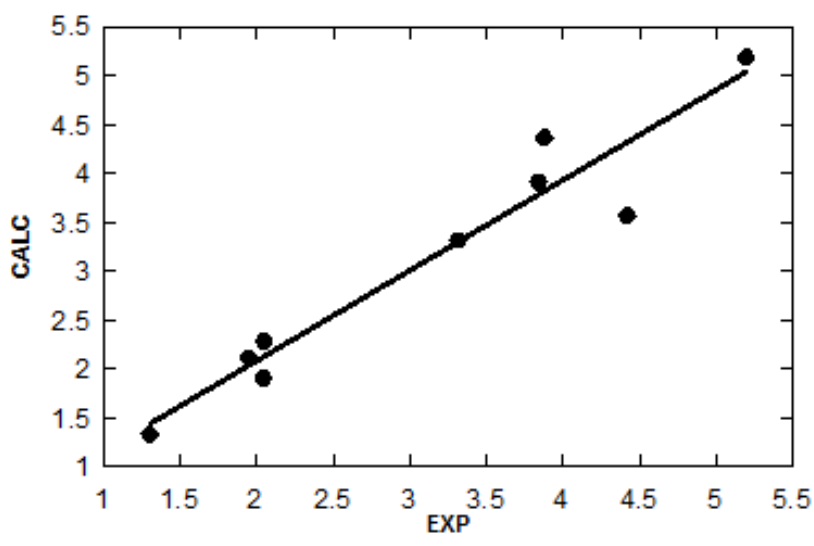

Fig 7. The relationships between experimental $(\eta)$ and predicted $(\eta)$ by model ( 6$)$. 


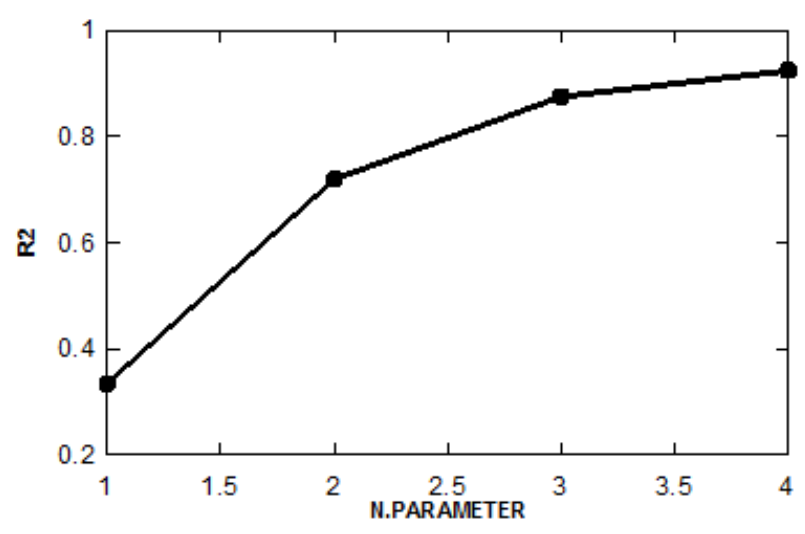

Fig. 8. Influence of number of parameters on R2 of MLR model

It is obvious that as the number of parameters increases the R2 will increase. Fig. 8, shows the effect of increasing the number of descriptors on $\mathrm{R} 2$ values. It can be seen from this figure that increasing the number of parameters only up to four has a large influence on improving correlation[14,25]. Therefore, we have chosen 13 descriptors as optimum number of parameters. one- and four-parameter models for each of anilne substituted, which it has less standard error (SE) high $\mathrm{F}$ values. In theTable 2 . The predicted viscosity $(\eta)$ values obtain from Eq. 5 and 6 , It is obvious from Table 2 . that the Relations between descriptors which calculated in this study and experimental viscosity $(\eta)$ values are in a very good accordance.

Table 2. Experimental data according to Eq. 5 and 6.

$\begin{array}{ccccc}\text { No. } & \text { Name } & { }^{*} \operatorname{Exp}(\eta) & \text { Calc }(\eta) \text { by eq } 5 & \text { Calc }(\eta) \text { by eq } 6 \\ 1 & \text { Aniline } & 3.877 & 4.015 & 4.360 \\ 2 & \text { O-Chloroaniline } & 3.316 & 3.645 & 3.315 \\ 3 & \text { N-Methyl aniline } & 2.042 & 2.278 & 1.905 \\ 4 & \text { N-Ethyl aniline } & 2.047 & 2.325 & 2.285 \\ 5 & \text { M-Toluidine } & 4.418 & 3.440 & 3.565 \\ 6 & \text { P- Toluidine } & 1.945 & 2.071 & 2.117 \\ 7 & \text { O-Toluidine } & 5.195 & 5.241 & 5.185 \\ 8 & \text { N,N- Diethylaniline } & 3.838 & 3.876 & 3.912 \\ 9 & \text { N,N- Dimethylaniline } & 1.3 & 1.083 & 1.329\end{array}$

${ }^{*} \operatorname{Exp}(\eta)$ in $\mathrm{mN}$. S. $\mathrm{m}^{-2}=\operatorname{Ref} 20$

\section{Conclusion}

The linear model and multiple regressions were performed between viscosity $(\eta)$ of anilne substituted and some chemical parameters/descriptors. The study indicated that viscosity for anilne substituted can be modeled. The values of $\mathrm{R}^{2}, \mathrm{~S}$ and $\mathrm{F}$ suggest that the QSPR models in Eqs from1 to 6 are predicted and validated. From all the results the Eq 6 . have small value of $S$ and large values of $F$ and $R^{2}$ that regard as better in QSPR model. The experimental and the predicted values using MLR model was excellent, and this model including [Volume, T.E, surface(A) and
Charge of $\mathrm{N}_{7}$ ] showed significant role in the viscosity $(\eta)$ of aniline compounds. It is evident from the results that the viscosity $(\eta)$ of the anilne substituted is influenced mainly by the four descriptors. Through the present results exemplified here, we can apply a similar approach to build other QSPR models for viscosity of such compounds of those models will likely provide more effective means in designing novel compounds which have different applications with improved profiles. This study may be helpful for the chemists and researcher to understanding parameters of viscosity of aniline compounds understudy.

\section{References}

1-Ranjit B, Sarika B, and Biman B., J. Phys. Chem. B, 102, 3252-3256, (1998).

2-Wazer, J. R., Viscosity and flow mesurement: a laboratory handbook of reology. New York: Interscience Publishers, (1963).

3-R.B. Bird, W.E. Stewart, and E.N. Lightfoot, Transport Phenomena,Wiley, New York (1960).

4- Symon, Keith. Mechanics(Thirded.). AddisonWesley. ISBN 0-201-07392-7.(1971).

5-"The Online Etymology Dictionary" (http://www.etymonline.com/index.php?te $\mathrm{rm}=$ viscous).Etymonline.com. Retrieved 201009-14.

6- Raymond A. Serway. Physics for Scientists \& Engineers (4th ed.). Saunders College Publishing. ISBN 0-03- 005932-1,(1996)..

7- Reid, R. C.; Prausnitz, J. M.; Poling, B. E. Properties of Gases and Liquids, 4 th .ed;McGraw-Hill: New York, (1987).

8-T. A. Litovitz and C. M. Davis, Structural and shear relaxation in liquids: $\mathrm{In}$ : W. P. Mason (Ed.),Physical Acoustics: Principles and Methods, Vol. II, Part A, Properties of Gases, Liquids and Solutions,New York: Academic Press, , pp. 281-349.(1965).

9- Ewelina WĘGLARZ-TOMCZAK,Łukasz GO'RECKI, CHEMIK, , 66,12, 12981307,(2012).

10- Scarfe GB, Wilson ID, Warne MA, Holmes E, NicholsonJK,lindon

JC.,Xenobiotica. 32(4):267-77.Apr(2002).

11- Xia-Li Yue, Hu Li, Shuang-Shuang Liu, Qing-Ye Zhang, Jing-Jing Yao, Fei-Yan Wang.,Chinese Chemical Letters .25 1069-1072,(2014). 
12-Peixun Liu and Wei Long, Int. J. Mol. Sci., 10, 1978-1998,(2009);doi:10.3390/ijms10051978 .

13- M. Dehmer, K. Varmuza, and D.Bonchev, Statistical Modelling of Molecular Descriptors in QSAR/QSPR. $1^{\text {st }}$.ed. (2012)

Wiley-VCH Verlag GmbH \& Co. KGaA.

Published 2012 by Wiley-VCH Verlag GmbH \& Co. KGaA.

14- Rudolf Kiralj and Ma'rcia M. C. Ferreira. J. Braz. Chem. Soc., Vol. 20, No. 4, 770787, (2009).

15- Lorentz JÄNTSCHI, Leonardo Journal of Sciences., Issue 4, January-June, p.68-85. (2004).

16-Majid S and Hassan G,.European Journal of Chemistry.1(4),266-275.(2010).

17- Ovidiu Ivanciuc,Teodora Ivanciuc,Petru Filip, and Daniel Cabrol-Bass., J. Chem. Inf.Comput. Sci., 39, 515-524,(1999).

18- Hong Wei Xiang,Arno Laesecke, and Marcia L. Huber., J. Phys. Chem. Ref. Data, Vol. 35, No. 4, (2006).

19- Bono Lučić, Ivan Bašic, Damir Nadramija, Ante Miličević, Nenad Trinajstić, Takahiro Suzuki, Ruslan Petrukhin, Mati Karelson,and Alan R. Katritzky, ARKIVOC, 2002 (iv) 45-59,(2002).

20- John A. Dean., LANGE'S HANDBOOK OF CHEMISTRY., $15^{\text {th }}$..ed,. Copyright,by McGraw-Hill, Inc.(1999).

21- Frisch M. J., Trucks ,G. W., Schlegel , H. B., Scuseria, G. E., Robb, M. A., Cheeseman, J. R., Montgomery Jr, J. A., Vreven , T., Kudin, K. N., Burant, J. C., Millam ,J. M., S. S., Iyengar, J.,Barone, V., Mennucci ,B., Cossi, M., Scalmani ,G., Rega, N., Petersson ,G. A., Nakatsuji „H., M., Hada., Ehara M., Toyota, K., Fukuda, R., J., Ishida, M., Nakajima ,T., Honda, Y., Kitao, O., H., Klene, M., Knox, X. Li. J. E., Hratchian, H. P., Cross, J. B., Bakken, V., Adamo, C. Jaramillo, J., Gomperts, R., Stratmann, R. E., Yazyev, O., Austin, A. J., Cammi, R., Pomelli, C.,Ochterski, J. W., Ayala, P. Y., Morokuma, K., Voth, G. A., Salvador, P., Dannenberg, J. J., Zakrzewski, V. G., Dapprich, S., Daniels, A. D., Strain, M. C., Farkas, O., Malick, D. K., Rabuck, A. D., Raghavachari, K., Foresman, J. B., Ortiz, J.V.,Cui,Q.,Baboul,A.G.,Clifford,S., ioslowski, J., Stefanov, B. B., Liu,G., Liashenko, A., Piskorz, P.,Komaromi, I., Martin, R.L., Fox, D.
J., Keith, T. Gaussian Inc.,Waling ford, CT,

[2004]. Available online. www . gaussian.com.

22- a- Becke D, J chem Phys., 98, 56485652(1993). b- C. Lee. W. Yang and R. G. Parr. Phys. Rev. Lett.B37, 785-789(1998).

c- J.P. Perdew, K. Burke and Y. Wang. Phys. Rev,.B54, 16533, (1996). d- J.P. Perdew, J. A. Chevary, S. H. Vosko, K. A. Jackson, M. R. Peerson, D. J. Singh and C. Fiolhais, Phys. Rev. B48, 4979, (1993).

23- Vladyslav. K, Jack. R.S, Doyle K, Sascha.A, Joachim .K, William J. Welsh, Polymer. 45 , 7367-7379,(2004).

24- Adrian. B, Ana. C. R, Marioara. B, Titus $\mathrm{C}$ and Alexandru T. B., Internet Electronic Journal of Molecular Design, 5, 237-246.(2006).

25- Bulusu. G, Natesan. S,Akash.K, Jagattaran D, Shaikh. A. R, Sanjay.T, and Magadi S. K. J. I.,Bioorganic \& Medicinal Chemistry, 11 $.2569-2574 .(2003)$. 